\title{
Influence of a Liquid Nutritional Supplement on Water Intake in Experimental Beagle Dogs
}

\author{
Christelle Rotat ${ }^{1}$, Estelle Lhoest ${ }^{1}$, Anaelle Rauw ${ }^{1}$, Marjorie Dequenne ${ }^{1 *}$, \\ Wim Van Kerkhoven ${ }^{2}$, Marianne Diez ${ }^{1}$ \\ ${ }^{1}$ Nutrition Unit, Department of Animal Production, Faculty of Veterinary Medicine, University of Liège, Liège, \\ Belgium \\ ${ }^{2}$ Viyo International NV Ijzerenpoortkaai, Antwerpen, Belgium \\ Email: "mdiez@ulg.ac.be
}

Received 5 April 2016; accepted 25 April 2016; published 28 April 2016

Copyright (C) 2016 by authors and Scientific Research Publishing Inc.

This work is licensed under the Creative Commons Attribution International License (CC BY). http://creativecommons.org/licenses/by/4.0/

(c) (i) Open Access

\section{Abstract}

The objectives were to evaluate the effects of a liquid nutritional supplement formulated for dogs on water intakes and urine output. A liquid nutritional supplement was tested by way of a crossover design in 8 experimental healthy Beagle dogs ( 4 males and 4 females, aged 9.3 years). The supplement (87 percent water, 2.7 percent protein, 2.6 percent fat, 0.4 percent crude fiber) was added to water and tested at 2 incorporation rates $(50$ or $70 \mathrm{ml} / \mathrm{day} / \mathrm{dog}-\mathrm{D} 50$ or D70) versus the control placebo (CO-water only). The dogs were kept in a controlled environment; water intakes and urine output were measured. Individual water intakes were characterised by large variations. Mean water intake increased significantly by 28 percent in dogs receiving the liquid nutritional supplement, in both genders, irrespectively of the dosage. Urine output was also increased, by 55 percent. Faeces scores remained unchanged. It was concluded that the liquid supplement increased water intake and urine output in a safe way, without increasing dramatically the daily dietary sodium chloride intake. The recommended dosage of the manufacturer $-50 \mathrm{ml} / \mathrm{day}$ for dogs weighing 10 - $20 \mathrm{~kg} \mathrm{BW}$ is efficient. Increasing the dosage had no advantage, nor adverse effects. Increased water intake and urine output is of interest for dogs suffering from urolithiasis.

\section{Keywords}

Dog, Water Intake, Liquid Supplement, Urine Output

\footnotetext{
${ }^{*}$ Corresponding author.
}

How to cite this paper: Rotat, C., Lhoest, E., Rauw, A., Dequenne, M., Van Kerkhoven, W. and Diez, M. (2016) Influence of a Liquid Nutritional Supplement on Water Intake in Experimental Beagle Dogs. Open Journal of Veterinary Medicine, 6, 69-74. http://dx.doi.org/10.4236/ojvm.2016.64008 


\section{Introduction}

Water is an essential nutrient, but perhaps the least discussed with respect to dietary requirements. Although dogs used to drink spontaneously, it can be interesting to stimulate water intake in dogs suffering from urolithiasis, especially in small breeds. In small breeds, the predisposition to urolithiasis may indeed be related to their lower urine volume, fewer numbers of micturitions and therefore increased mineral concentrations [1]. Moreover, the major factor in managing and preventing urolithiasis recurrence in dogs and cats is to stimulate diuresis.

In the present experiment, the effects of a liquid nutritional supplement formulated for dogs on water intake and urine output were examined in experimental Beagle dogs.

\section{Materials and Methods}

\subsection{Animals and Feeding}

Eight experimental Beagle dogs ( 4 neutered males and 4 neutered females; age $=9.3$ years), weighing 13.8 to $23.0 \mathrm{~kg}$ (mean $\pm \mathrm{sd}, 19 \pm 2.9 \mathrm{~kg}$ ) were used in 2 studies, in a cross-over design. Dogs were housed in the animal facilities of the veterinary faculty of Liège, in metabolism cages $(0.8 \times 1.0 \mathrm{~m})$ to allow faeces and urine collection. The mean room temperature during the studies was $20.2^{\circ} \mathrm{C} \pm 1.9^{\circ} \mathrm{C}$. All dogs were vaccinated and dewormed 4 weeks before the 2 studies. Body Weight (BW) was controlled before the studies and once a week during the experiments. Dogs were fed once a day at 9 AM with their usual food, a dry high fat diet formulated to meet maintenance requirements (Table 1). Energy contribution from protein, fat and carbohydrates was 24, 49 and 27 percent, respectively; the metabolizable energy content was $4200 \mathrm{kcal} / \mathrm{kg}$ as fed. The dogs were fed for the experiment at a fixed energy level that maintained stable BW.

The liquid supplement (chemical composition as if: 87 percent water, 2.7 percent protein, 2.6 percent fat, 0.4 percent crude fiber) was added to tap water twice a day, control dogs (CO) receiving the same amount of tap water instead of the supplement. The daily dosage was $50 \mathrm{ml}$ (D50) in study 1 and $70 \mathrm{ml}$ (D70) in study 2 . The water (with supplement-D50 and D 70 or without supplement-CO) was given according to the following design: at 9 (after the meal) and 12 AM: $500 \mathrm{ml}$ water +25 (or 35) $\mathrm{ml}$ supplement (for respectively study 1 (D50) and 2 (D70), corresponding to 50 or $70 \mathrm{ml} / \mathrm{dog} / \mathrm{day}$ ) or 25 (35) $\mathrm{ml}$ water (CO). At $4 \mathrm{PM}$, all dogs (groups D50, D70 and CO) were given $1500 \mathrm{ml}$ water. The design was set to test the short term effect of adding the supplement on water intake since actually, kennel dogs normally drink after feeding.

The composition of the supplement in per cent DM is given in Table 1. The ingredients of the liquid nutritional supplement are: water, meat, meat by-products, plant by-products, fat, milk and milk by-products, minerals, yeast, inulin, fructooligosaccharides.

Physical examination, biochemistry profiles (glucose, total protein, albumin, liver enzymes, creatinine, urea, total cholesterol), $\mathrm{CBC}$ and urinalysis were determined for each $\operatorname{dog} 3$ days before entering the first study; the second study was conducted immediately after the first.

The protocol was approved by the Animal Use Advisory Committee of the University of Liège.

\subsection{Experimental Design}

The experiment consisted of a cross-over design and included males and females respectively (Study 1: CO vs. D50). During week 1, males (2 CO, 2 D50) were put in metabolism cages and measurements were made during 5 days; after 2 days of wash-out, the treatments were changed for the second week of the cross-over. The same experiment was made with females during the 2 following weeks. And finally, 2 males and 2 females were used in a 2 weeks crossing-over to test the effects of a higher dosage of the supplement in the study 2: $70 \mathrm{ml} / \mathrm{dog} /$ day (group D70).

\subsection{Measurements}

Water intake was measured 4 times a day (9,10 and $12 \mathrm{AM}$ and $4 \mathrm{PM})$. Total urine was measured once a day at 9 AM; urine density was determined at the end of each week with a refractometer. Faeces scores (from 1-dry-to 5-watery) were measured daily.

\subsection{Statistics}

The observed variations in water intake and urine output were analysed with a linear fixed effect model that in- 
cluded gender, treatment (CO, D50, D70), week (periods of measurement) and time (day 1 to 5 nested within the week effect) (Proc GLM, SAS Institute 2002) [2]. The analysis was performed separately for water intake from $9 \mathrm{AM}$ to $4 \mathrm{PM}$ and from $4 \mathrm{PM}$ to $9 \mathrm{AM}$. Least squares means were compared and differences were considered as significant if the $\mathrm{P}$ value was less than 0.05 .

\section{Results}

According to physical examination, appetite and behaviour, all the dogs stayed healthy during the 2 studies. All dogs consumed their daily food allowance completely. The mean metabolizable energy supply was $103 \mathrm{kcal} / \mathrm{kg}$ $\mathrm{BW}^{0.75}$ (ranges: 94 - 114). The inclusion of the supplement induced minor changes in the chemical composition in the whole diet (Table 1).

The statistical analysis revealed that significant differences were found between groups CO and D50 (study 1) and between groups CO and D70 (study 2), both for water intakes and urine output. Significant differences were also found between genders (Table 2).

\subsection{Water Intake}

The water intakes are given in (mean $\pm \mathrm{sd}$ ) $\mathrm{ml} / \mathrm{kg} \mathrm{BW}$ (Table 2). Individual water intakes were characterised by high variations, from 54 to $108 \mathrm{ml} / \mathrm{kg} \mathrm{BW}$, according to treatment (CO versus D50 or D70), gender and the dosage of the liquid supplement. In dogs that used to drink a lot, the addition of the liquid supplement had less influence on water intake, compared with dogs drinking normally.

Total water intake and water intake in $\mathrm{ml} / \mathrm{kg}$ BW were significantly increased with the supplement in both genders. The effect appeared directly, in the minutes following the addition of the supplement to the water bowl. When dogs were receiving the first part of the supplement added to water at $9 \mathrm{AM}$, in both studies, they used to drink it immediately, so that the bowls of the supplemented dogs (D50 or D70) were empty at 10 AM. The liquid supplement increased significantly water intake in the period of 9 AM to 4 PM, not in the period of 4PM to 9AM (Table 2).

On the $24-\mathrm{H}$ period water intake was increased by 28 percent in dogs receiving the liquid nutritional supplement at the dosage of 50 or $70 \mathrm{ml} /$ day.

Table 1. Chemical composition of the diet (Control), the liquid nutritional supplement and both treatments in the 2 studies.

\begin{tabular}{ccccc}
\hline & $\begin{array}{c}\text { Control } \\
\text { (Studies 1 - })\end{array}$ & $\begin{array}{c}\text { Liquid supplement** } \\
\text { (studies 1 - 2) }\end{array}$ & $\begin{array}{c}\text { Treatment-D50 } \\
\text { (Study 1) }\end{array}$ & $\begin{array}{c}\text { Treatment-D70 } \\
\text { (Study 2) }\end{array}$ \\
\hline & Diet & & Diet + 50 ml drink & Diet + 70 ml drink \\
\hline \% DM* & \% DM & 30.2 & 30.1 \\
\hline Crude Protein (\%) & 30.5 & 21.4 & 26.8 & 26.7 \\
Ether Extract (\%) & 27.0 & 20.6 & 34.8 & 34.9 \\
Nitrogen free extract (\%) & 34.5 & 45.2 & 2.1 & 2.1 \\
Crude Fibre (\%) & 2.1 & 3.2 & 6.0 & 6.1 \\
Crude Ash (\%) & 5.9 & 9.6 & 1.03 & 1.04 \\
Calcium (\%) & 1.01 & 1.65 & 0.75 & 0.75 \\
Phosphorus (\%) & 0.75 & 0.63 & 0.37 & 0.37 \\
Sodium (\%) & 0.35 & 0.94 & 0.82 & 0.83 \\
Potassium (\%) & 0.80 & 1.59 & 0.09 & 0.09 \\
Magnesium (\%) & 0.09 & 0.08 & 0.11 & 0.12 \\
Taurine (\%) & 0.10 & 0.56 & 13,075 & 13,252 \\
Vitamin A (UI/kg) & 12,616 & 28,254 & 837 & 919 \\
Vitamin D (UI/kg) & 622 & 7937 & 649 & 648 \\
Vitamin E (mg/kg) & 649 & 634 & & \\
\hline
\end{tabular}

*DM, dry matter; **Ingredients: Water, maltodextrine, soluble fibre (wheat), modified starch (maize), highly pure cellulose, lecithine (soy—non GMO), inulin, guar gum, oligofructose, xanthan gum, poultry meat, vegetable oil (rapeseed), poultry fat, calcium carbonate, K-carbonate, manganese-sulphate, zinc-gluconate, sodium tripolyphosphate STPP, cream powder (lactose free), vitamin-mineral mix. 
Table 2. Water intakes and urine output (mean $\pm \mathrm{sd}$ ) in experimental Beagle dogs receiving 50 (Study 1$)$ or $70 \mathrm{ml} / \mathrm{day}$ (Study 2) of a liquid nutritional supplement versus Control.

\begin{tabular}{|c|c|c|c|c|c|}
\hline & & & \multicolumn{2}{|l|}{ Drinking Water } & \multirow{2}{*}{$\begin{array}{l}\text { Urine output } \\
\mathrm{ml} / \mathrm{kg} \mathrm{BW}\end{array}$} \\
\hline & & & $\mathrm{ml} / \mathrm{kg} \mathrm{BW}$ & & \\
\hline & Time & $9 \mathrm{AM}$ to $4 \mathrm{PM}$ & $4 \mathrm{PM}$ to $9 \mathrm{AM}$ & $24 \mathrm{~h}$ & $24 \mathrm{~h}$ \\
\hline \multicolumn{6}{|c|}{ Study 1: CO vs Supplement $50 \mathrm{ml} / \mathrm{d}$} \\
\hline \multirow[t]{2}{*}{ Males $(n=4)$} & $\mathrm{CO}$ & $47 \pm 11$ & $20 \pm 7$ & $67 \pm 18$ & $40 \pm 11$ \\
\hline & D50 & $55 \pm 6^{*}$ & $31 \pm 14$ & $87 \pm 18^{*}$ & $59 \pm 6^{*}$ \\
\hline \multirow[t]{2}{*}{ Females $(n=4)$} & $\mathrm{CO}$ & $40 \pm 9$ & $49 \pm 10$ & $88 \pm 19$ & $70 \pm 28$ \\
\hline & D50 & $58 \pm 11^{*}$ & $50 \pm 21$ & $108 \pm 12 *$ & $97 \pm 11^{*}$ \\
\hline \multirow[t]{2}{*}{ All dogs $(n=8)$} & $\mathrm{CO}$ & $43 \pm 10$ & $34 \pm 17$ & $78 \pm 20$ & $55 \pm 25$ \\
\hline & D50 & $57 \pm 9^{*}$ & $40 \pm 20$ & $97 \pm 18^{*}$ & $78 \pm 22^{*}$ \\
\hline \multicolumn{6}{|c|}{ Study 2: CO vs Supplement $70 \mathrm{ml} / \mathrm{d}$} \\
\hline \multirow[t]{2}{*}{ Males $(n=2)$} & $\mathrm{CO}$ & $37 \pm 5$ & $16 \pm 2$ & $54 \pm 6$ & $33 \pm 8$ \\
\hline & D70 & $51 \pm 6^{*}$ & $23 \pm 10$ & $74 \pm 4$ & $51 \pm 2 *$ \\
\hline \multirow[t]{2}{*}{ Females $(\mathrm{n}=2)$} & $\mathrm{CO}$ & $47 \pm 5$ & $35 \pm 19$ & $82 \pm 23$ & $59 \pm 25$ \\
\hline & D70 & $54 \pm 1$ & $42 \pm 26$ & $95 \pm 26$ & $74 \pm 20^{*}$ \\
\hline \multirow[t]{2}{*}{ All dogs $(n=4)$} & $\mathrm{CO}$ & $42 \pm 7$ & $25 \pm 15$ & $68 \pm 21$ & $46 \pm 22$ \\
\hline & D70 & $52 \pm 3$ & $32 \pm 19$ & $84 \pm 20^{*}$ & $63 \pm 18^{*}$ \\
\hline
\end{tabular}

$\mathrm{CO}$, Control, D50 and D70, liquid nutritional supplement at the dosage of 50 or $70 \mathrm{ml} /$ day; *significant differences $(\mathrm{P}<0.05)$ between treatments within a column.

\subsection{Urine}

Total urine output was also significantly and dramatically increased by 55 and 47 percent in respectively, study 1 (D50) and 2 (D70) (Table 2). Urine density was decreased compared to control but stayed in normal ranges (CO: $1018 \pm 8$ versus $1012 \pm 8$ for D50).

\subsection{Faeces}

The faeces score was measured daily; we observed no significant difference during the 2 studies: the overall mean was 2.51 (ranges: 2.0 - 3.5); it was similar in CO, D50 and D70 groups.

\section{Discussion}

In dogs, loss of water occurs primarily as a function of respiration and production of urine and faeces. While water losses are continual through the day, access to water by terrestrial animals such as dogs and cats is periodic. According to Ramsay and Thrasher [3], thirst is directly correlated with body water content and plasma osmolality and intake may not be stimulated until a mild degree of dehydration exists. Despite that observation, the dogs used in these studies experienced an increase of water intake, due to the appetizing liquid nutritional supplement added in tap water. Actually, this effect appeared immediately: our dogs receiving the supplement used to drink all their water in the minutes following the addition of the supplement.

It must be outlined that adding salt is known to increase dramatically water intake, especially in cats but it is not the case in this trial since adding the liquid supplement induced only a slight increase in daily salt content: 0.37 (D50, D70) vs 0.35 percent $\mathrm{Na}$ (CO).

Water needs can be met by a combination of water consumed voluntarily (free water), water as a component of food (combined water), or water produced endogenously during the metabolism of energy-containing nutrients (metabolic water) [4].

Several formulas have been used to estimate daily needs for maintenance of normal water balance. The simplest is based solely on BW. The daily water need estimated by this formula is $50-60 \mathrm{ml} / \mathrm{kg} \mathrm{BW}$ [5]. In this study, the dogs used to drink more, from $68 \pm 21$ (CO) to $97 \pm 18$ (D50) $\mathrm{ml} / \mathrm{kg} \mathrm{BW} /$ day; this data is very close to 
$91 \mathrm{ml} / \mathrm{kg} \mathrm{BW} / \mathrm{d}$ or $109 \mathrm{ml} / \mathrm{kg} / \mathrm{d}$ as previously published for experimental dogs [6] [7]. The environment of laboratory dogs is unusual in that water is always available; thus we can postulate that dogs kept in metabolism cages actually used to drink much more than a pet dog.

Factors affecting a pet's voluntary water consumption include the ambient temperature, type of diet that is fed, level of exercise [8], physiological state, and health.

The amounts of energy that are consumed affect voluntarily water consumption: as energy intake increases, more metabolic products are produced and the heat produced by nutrient metabolism increases. In these circumstances, the body requires more water to excrete waste products in the urine and to contribute to thermoregulation. Since water needs appear to be highly associated with amount of food consumed, other formulas that estimate needs based on food intake provide a broader range of circumstances than one based on BW [9] [10].

The amount of water derived directly from food depends on the type of food. Since a dog eating only canned food may not voluntarily consume free water, we choose to use dry food for the experiment. The dry dog food contained 7.5 percent moisture, while canned foods usually exceed 75 percent moisture.

Water intake increases with both increasing environmental temperature and increasing exercise because more evaporative water is lost as a result of the body's cooling mechanisms. Panting substantially increases respiratory water loss and thus heat loss. Because of these mechanisms of temperature regulation, water losses from respiration and evaporation during hot weather can be very high in dogs.

As the dogs were kept in metabolism cages in similar conditions during the 2 studies, they had little exercise. Thus it is reasonable to hypothesize that this route of water loss may have been low and comparable between the dogs. Moreover, drinking behaviour and water exchanges of dogs living in metabolism cages has been extensively studied [6].

All animals experienced daily water losses. Urinary excretion accounts for the greatest volume of loss in most animals; it is thought that 70 percent of the daily water intake is excreted in the urine. Obligatory fluid loss from the kidneys is the minimum that is required for the body to rid itself of the daily load of urinary waste products. A certain quantity of water is necessary to act as a solvent for these end products. The remaining portion of urinary water loss, called facultative loss, is excreted in response to the normal water re-absorption rate of the kidney and to mechanisms responsible for maintaining proper water balance in the body. Faecal water accounts for a much smaller portion of water excretion, about 7 per cent of total water intake [11]. The amount of water that actually appears in the faeces is very low compared to the amount that is absorbed across the gastrointestinal tract and returned to the body during digestion. Faecal water loss becomes substantial only when aberrations in intestinal capacity to absorb water occur. In the 2 studies reported here, urine output was dramatically increased, in proportion to water intakes. We did not measure faeces weight but we did the faeces scoring, as an indicator of digestive tolerance: the faeces score was unchanged for both concentrations of the supplement, compared to the control dogs.

\section{Conclusion}

We can conclude that the liquid nutritional supplement has increased water intake and urine output, without increasing dramatically the daily dietary sodium chloride intake. The recommended dosage of the manufacturer$50 \mathrm{ml} /$ day for dogs weighing $10-20 \mathrm{~kg} \mathrm{BW}$ is efficient. Increasing the dosage had no advantage, nor visible adverse effects. According to the manufacturer, the liquid nutritional supplement can be used alone, for example, on the food to stimulate appetite, which is highly recommended in hospitalised dogs [12]. Indeed, within limits, increasing the water content of pet foods increases the diet's acceptability. It can be also added to water to increase intake for other conditions; for example, in dogs suffering from urolithiasis [13] or in sports dogs, to avoid the risk of dehydration.

\section{References}

[1] Stevenson, A.E. and Markwell, P.J. (2001) Comparison of Urine Composition of Healthy Labrador Retrievers and Miniature Schnauzers. American Journal of Veterinary Research, 62, 1782-1786. http://dx.doi.org/10.2460/ajvr.2001.62.1782

[2] SAS Institute Inc. (2002) SAS/Stat User's Guide. Version 9, Cary, NC.

[3] Ramsay, D.J. and Trasher, T.N. (1991) Regulation of Fluid Intake in Dogs Following Water Deprivation. Brain Research Bulletin, 27, 495-499. http://dx.doi.org/10.1016/0361-9230(91)90148-D 
[4] NRC (2006) Nutrient Requirements of Dogs and Cats. The National Academies Press, Washington DC, 398 p.

[5] Schaer, M. (1989) General Principles of Fluid Therapy in Small Animal Medicine. Veterinary Clinics of North America Small Animal Practice, 19, 203-213. http://dx.doi.org/10.1016/S0195-5616(89)50026-3

[6] O'Connor, W.J. and Potts, D.J. (1969) The External Water Exchanges of Normal Laboratory Dogs. Quarterly Journal of Experimental Physiology, 54, 244-265. http://dx.doi.org/10.1113/expphysiol.1969.sp002022

[7] Kaczmarczyk, G., Boemhe, W., Zahrei-fard, D. and Braun, H. (1995) High Water Intake Combined with Low Sodium Intake Abolishes the Antidiuretic Effect of Angiotensin II in Conscious Dogs. Clinical Sciences, 89, 19-25. http://dx.doi.org/10.1042/cs0890019

[8] O'Connor, W.J. (1975) Drinking by Dogs during and after Running. Journal of Physiology, 250, 247-259. http://dx.doi.org/10.1113/jphysiol.1975.sp011052

[9] Case, L.P., Carey, D.P., Hirakawa, D.A. and Daristotle, L. (2000) Energy. In: Duncan, L.L., Ed., Canine and Feline Nutrition: A Resource for Companion Animals Professionals, 2nd Edition, MOSBY, St Louis, 5-15.

[10] Lewis, L.D., Morris, M.L. and Hand, M.S. (1987) Nutrients in Small Animal Clinical Nutrition. 3rd Edition, Mark Morris Associate, Topeka, 1-2.

[11] Buffington, C.A., Holloway, C. and Abood, S.K. (2004) Clinical Dietetics. In: Manual of Veterinary Dietetics, Saunders, Philadelphia, 49-141.

[12] Delaney, S.J. (2006) Management of Anorexia in Dogs and Cats. Veterinary Clinics of North America Small Animal Practice, 36, 1243-1249. http://dx.doi.org/10.1016/j.cvsm.2006.08.001

[13] Picavet, P., Detilleux, J., Verschuren, S., Sparkes, A., Lulich, J., Osborne, C., Istasse, L. and Diez, M. (2007) Analysis of 4495 Canine and Feline Uroliths in the Benelux. A Retrospective Study: 1994 - 2004. Journal of Animal Physiology and Animal Nutrition, 91, 247-251. http://dx.doi.org/10.1111/j.1439-0396.2007.00699.x 